\title{
ELECTROGMYOGRAPHIC FEATURES OF MUSCLES SOLEUS IN PEOPLE WITH THE INCREASED SENSITIVITY OF THE VESTIBULAR ANALYZER
}

\author{
Stepan Vadzyuk ${ }^{1}$ \\ vadzyuk@tdmu.edu.ua \\ Roman Shmata \\ roman@tdmu.edu.ua \\ Nataliia Ulianytska \\ Department of human health and physical therapy \\ Lesya Ukrainka Eastern European National University \\ 13 Voli ave., Lutsk, Ukraine, 43025 \\ natali-ul@ukr.net \\ ${ }^{1}$ Department of physiology with the basios of bioethics and biosafety \\ I. Horbachevsky Ternopil National Medical University \\ 1 Voli sq., Ternopil, Ukraine, 46001
}

\begin{abstract}
The article deals with the features of electromyographic indicators of the soleus muscles while maintaining a upright position in people with increased vestibular sensitivity. From the literature, it is concluded that the study of electromyographic features of indicators in the conditions of irritation of the vestibular analyzer in people with different vestibular sensitivity is an important area in physiology. Vestibular sensitivity was determined by the questionnaire, Voyachek's sample and Fukuda's written test. To assess the electromyographic activity of the soleus muscles, a computer DX complex was used for registration of interference electromyography. Registration was carried out during performing Romberg test, before and after vestibular loading. According to the results of the vestibular irritation, there was a greater decrease in the amplitude of the flap muscles of the lower extremities in people with the increased vestibular sensitivity than in people with the adequate sensitivity. Based on the results achieved, it can be assumed, that in people with the increased sensitivity of the vestibular analyzer, the irritation of the receptors of the semicircular canals alters the activity of extensor motoneurons of the human spinal cord more significantly than in people with the adequate sensitivity.
\end{abstract}

Keywords: muscle soleus, increased vestibular sensitivity, Romberg test, vestibular analyzer, rotational test.

DOI: $10.21303 / 2504-5695.2020 .001191$

\section{Introduction}

The human body functions through information that comes from both the external and internal environment and is processed through sensory systems. Changes in the position of the body and head after pulses from the vestibular receptors to the vestibular nuclei are ensured by their numerous connections with other centers of the brain and spinal cord. The number of connections of the vestibular nuclei with many motor centers of the nervous system provides support for the position of the body, muscle tone, as well as movements of the eyeballs. Therefore, equilibrium is provided by vestibulo-spinal and vestibulo-ocular conduction pathways [1]. It is also known, that posture retention and control are a set of interactions between the musculoskeletal, visual, vestibular and skin systems [2]. The skeletal muscle is the effector system of the vestibular analyzer [3]. In the scientific literature there are works, devoted to the study of vestibular stability of children, both healthy and with disorders of the musculoskeletal system [4].

It is also known, that the specific nature of motor activity in situational sports, implies a complex nature of movement coordination, which is programmed by the higher departments of the central nervous system and implemented by the muscular system in the interaction of visual, vestibular, proprioceptive and tactile sensory systems [5]. Some studies have described the role of sensory systems in gymnastics [6]. Therefore, posture control involves many different underlying 
physiological systems that may be affected by the pathology or subclinical limitations [7]. Electromyography is one of the methods of assessing a muscle condition.

Therefore, the study of the features of electromyographic indicators in the conditions of irritation of the vestibular analyzer in people with different vestibular sensitivity is an important and relevant area of physiological research.

Aim: to evaluate electromigraphic features of soleus muscles while maintaining the upright position in people with te increased vestibular sensitivity.

\section{Materials and methods}

\section{1. Organization of the research}

60 students between the ages of 18-19 years were examined. The study was conducted at the Ministry of Health of Ukraine certified laboratory of psychophysiological research at the Department of Physiology with the Basics of Bioethics and Biosafety of I. Horbachevsky Ternopil National Medical University (Certificate No. 003/18).

The survey was conducted during the 2018-2019 school year. Prior to the survey, we received an informed consent from all participants. Our research does not contradict accepted bioethical standards of the Declaration of Helsinki, adopted by the General Assembly of the World Medical Association on Human Rights, the International Code of Medical Ethics and Laws of Ukraine and can be used in scientific work (decision of the commission on bioethics I. Horbachevsky Ternopil National Medical University, protocol No. 55 of November 4, 2019).

\section{2. Methods of investigation of vestibular illusion of anti-rotation}

The vestibular sensitivity was determined with a help of the questionnaire, Voyachek's test and Fukuda's written test $[8,9]$.

The questionnaire included anamnestic questions from the examinees regarding the functional status of the vestibular analyzer in the vestibulo-motor projection. This revealed the symptom of the increased vestibular sensitivity, such as the presence of balance disorders.

Voyachek's test is as follows: the subject is placed in a Barani chair with his eyes closed, tilting his torso forward $90^{\circ}$. Do 5 rotations in 10 seconds and after a 5 -second pause offer a sharp straighten and open your eyes.

The results were evaluated on the following scale:

0 - no reaction;

1 - deviation of the torso from the vertical to $5^{\circ}$;

$2-$ deviation of the torso from the vertical by $5-30^{\circ}$;

3 - deviation of the trunk from the vertical more than $30^{\circ}$, the fall of the subject.

The rotational test was carried out by using Barany's chair. The rotational test is based on the fact that as a result of rotation of the body, the movement of the endolymph occurs in semicircular canals. This movement causes irritation of the receptors of the ampullary apparatus, which is accompanied by the appearance of vestibular reactions.

The "Fukuda Written Test" is as follows: the subject is offered to write the number " 33 " in a closed-eyed column, with the hand not touching the table and paper.

The results were evaluated on the following scale:

0 points - column is straight;

1 - indirect column;

2 - the column deviates more than $30^{\circ}$;

3 - dysmetry.

\section{3. Methods of investigation of neurodynamic features}

The electromyographic activity of the soleus muscles was determined by using the computer DX complex system. The registration and recording were performed by the interference electromyography [10]. Superficial electromyography is a painless way to study the muscle activity. It consists in the imposition of flat metal electrodes on the skin and allows to obtain the most general picture of the state of the neuromuscular system. Interference myography - 
this study allows to record the bioelectric activity of the test muscle with the help of surface electrodes.

The Romberg test is a neurological test, used to assess a person's static coordination. It is based on the principles of maintaining equilibrium through proprioceptive sensitivity, vestibular function and vision.

We conducted a simple Romberg trial. The subject was standing with his feet closed and arms extended forward, first with his eyes open and then with his eyes closed.Registration was carried out during performing the Romberg test (with open and closed eyes), before and after the rotational test [11]. Such indicators were determined as average amplitude (mkV) and average frequency.

\section{4. Statisical Analysis}

Statistical processing of the data was performed in the program "BioStat 5" (2019, type of license - 1 PC) by the method of nonparametric statistics, determining the Wilcoxon's signed-rank test and the U - Mann-Whitney test [12].

\section{Results}

Based on the questionnaire, Voyachek's test and Fukuda's written test, the students were divided into 2 groups: with the proper and increased vestibular sensitivity (Table 1).

After analyzing Voyachek's test, the people with the high sensitivity of the vestibular analyzer we observed, the first and second degrees of reaction were found in them (Fig. 1).

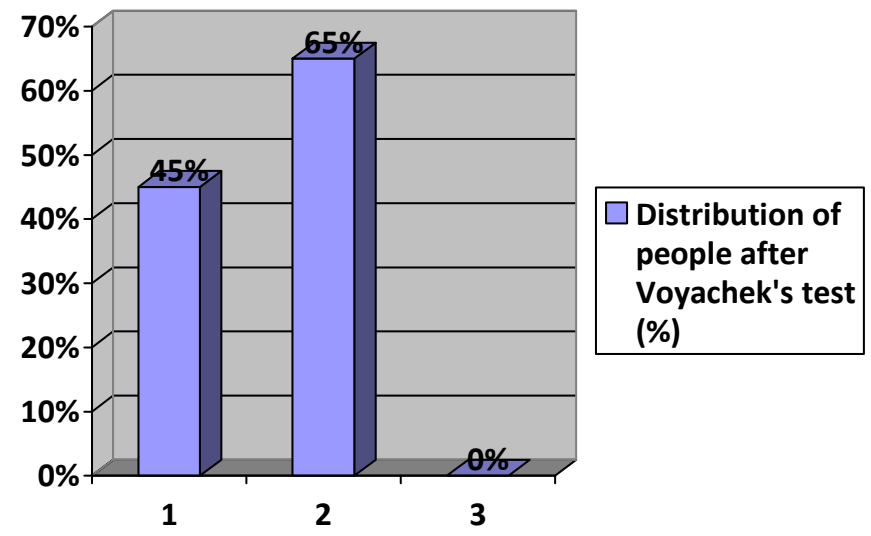

Fig. 1. Distribution of people with hypersensitivity to the vestibular analyzer after Voyachek's test (\%)

Among people with the proper vestibular sensitivity, we did not observe torso deviations during Voyachek's test, that is, they manifested 0 degree. The first degree was observed in people with the increased vestibular sensitivity, namely in $45 \%$, the second degree in $65 \%$ of the subjects. The third degree was not observed among our surveyed (Fig. 1).

When conducting Fukuda's written test among individuals with the proper vestibular sensitivity, we observed straight columns.

Among people with the increased vestibular sensitivity, we observed indirect columns in $60 \%$ of the subjects, and in $40 \%$ of the subjects, the column deviated more than $30^{\circ}$. We did not observe dysmetry among them.

In survey participants with the proper vestibular sensitivity during they were performing the Romberg test with the open eyes, the indicators of the interference electromyogram did not differ from those, recorded with the closed eyes. After the rotational test in this group the average amplitude during performing the Romberg test with the closed eyes was higher than with the open eyes $(\mathrm{p}<0.05)$.

In survey participants with the increased vestibular sensitivity, during performing the Romberg test with the eyes open, the average amplitude indicators were higher than those, recorded 
with the closed eyes. After the rotational test, in this group, the average amplitude decreased in the Romberg test, both with the closed and open eyes $(p<0.05)$. However, while performing the Romberg test with the closed eyes, it was lower than with the opened eyes $(p<0.05)$.

Table 1

Comparative interference electromyography of soleus muscles in subjects with different vestibular sensitivity when they are performing Romberg test with open and closed eyes

\begin{tabular}{|c|c|c|c|c|}
\hline & \multicolumn{2}{|c|}{ Before rotational test $\mathbf{n}-\mathbf{3 0}$} & \multicolumn{2}{|c|}{ After rotational test $\mathbf{n - 3 0}$} \\
\hline & \multicolumn{4}{|c|}{ Average amplitude (mkV) } \\
\hline & PR & IF & PR & IF \\
\hline When performing Romberg test with open eyes & 130,6 & 131,2 & 128,8 & $120,8 \diamond ; *$ \\
\hline When performing Romberg test with closed eyes & 133,3 & $110,2 \cdot ; *$ & 136,4 • & $98,2 \cdot ; ; * *$ \\
\hline \multicolumn{5}{|c|}{ Frequency average, $\mathrm{Hz}$} \\
\hline When performing Romberg test with open eyes & 128,5 & 127,2 & 123,5 & 124,3 \\
\hline When performing Romberg test with closed eyes & 130,5 & $132,1 \cdot$ & $128,5=$ & $138,4 \cdot ; ; * *$ \\
\hline \multicolumn{5}{|c|}{$\begin{array}{l}\text { Note: " p-statistical reliability according to Wilcoxon T-test in a homogeneus group, when they are performing Romberg test } \\
\text { with closed eyes; } \\
p^{*} \text { - statistical reliability according to Wilcoxon T-test in a homogeneus group after the rotational test; } \\
\text { increased vestibular sensitivity; PR - the proper sensitivity of the vestibular analyzer; IF -the increased sensitivity of the } \\
\text { vestibular analyzer }\end{array}$} \\
\hline
\end{tabular}

The average frequency increased during performing the Romberg test with the closed eyes in the group with the proper vestibular sensitivity after the rotational test $(p<0.05)$. In the group with the increased vestibular sensitivity the increase in average frequency was observed during performing the Romberg test with the closed eyes both before and after the rotational test $(\mathrm{p}<0.05)$. However, after the rotational test, in these individuals the index was higher than with the opened eyes during performing the Romberg test with their eyes closed $(\mathrm{p}<0.05)$.

Comparing of the average amplitude recorded during the Romberg test with the rotational test between groups in survey participants with increased vestibular sensitivity observed lower rates with closed eyes than in the group with proper sensitivity $(\mathrm{p}<0.05)$. While performing the Romberg test with opened eyes, the average amplitude indicators between groups did not differ.

Comparing the average amplitude, recorded during the Romberg test after the rotational test between groups, we found significantly lower indicators in the group with the increased vestibular sensitivity than in the group with the proper one, with both open and closed eyes $(p<0.05)$. The difference of the average frequency between groups, depending on the sensitivity of the vestibular analyzer, namely, the increasing of freguency, when the visual control is turned off in people with the increased vestibular sensitivity, indicates the compensation of maintaining the equilibrium.

Since the amplitude of interference electromyography is determined by the activation of additional motor units, and frequency is determined by the frequency of impulses of motoneurons, so it is interpreted as an indicator of the strength of muscle contraction [13]. Therefore, evaluating our results, we can assume that individuals with the increased vestibular sensitivity will obviously have less muscle contractions than those with a proper one.

Also, we found that the value of the amplitude and frequency change during maintaining an upright position under or without the control of the visual analyzer, namely, in people with the increased vestibular sensitivity, the value of the electromyogram amplitude is significantly lower than in people with the proper sensitivity and closed eyes. This is due to the fact that central and peripheral vision play a compensating role in maintaining the upright position [5]. It is indicated by our results, which are registered during performing the Romberg test with the closed eyes after the vestibular load in people with the increased sensitivity of the vestibular analyzer. The reason is that the lack of visual information leads to a decrease in the ability to maintain body balance under the 
influence of rectilinear accelerations on the vestibular analyzer. So, there are differences in the regulation of body balance mostly in people with the increased vestibular sensitivity and closed eyes.

\section{Conclusions}

In individuals with the increased vestibular sensitivity, the decrease in the amplitude of the electromyogram of the soleus muscles $(\mathrm{p}<0.05)$ was greater, when the vestibular system was irritated than in individuals with the proper sensitivity.

The results of our research make us suggest that the stimulation of the semicircular channel receptors changes the activity of the extrasensory motoneurons of the spinal cord in individuals with hypersensitivity of the vestibular analyzer more than in individuals with the proper sensitivity.

The obtained data can be taken into account in the examination in medical establishments and in the professional selection. They can also be used for educational purposes in medical universities. Since we did not consider gender in this study, therefore in the future we plan to explore a similar study in girls with the increased vestibular sensitivity in different phases of the menstrual cycle.

\section{References}

[1] Trinus, K., Claussen, C.-F. (2017). International Clinical Protocol on Vestibular Disorders (Dizziness). The International Tinnitus Journal, 21 (2). doi: https://doi.org/10.5935/0946-5448.20170029

[2] Carini, F., Mazzola, M., Fici, C., Palmeri, S., Messina, M., Damiani, P., Tomasello, G. (2017). Posture and posturology, anatomical and physiological profiles: overview and current state of art. Acta bio-medica: Atenei Parmensis, 88 (1), 11-16.

[3] Dakin, C. J., Héroux, M. E., Luu, B. L., Inglis, J. T., Blouin, J.-S. (2016). Vestibular contribution to balance control in the medial gastrocnemius and soleus. Journal of Neurophysiology, 115 (3), 1289-1297. doi: https://doi.org/10.1152/jn.00512.2015

[4] Pomeshchikova, I., Iermakov, S., Bartik, P., Shevchenko, O., Nosko, M., Yermakova, T., Nosko, Y. (2016). Influence of exercises and games with ball on vestibular stability of students with muscular-skeletal apparatus disorders. Sport Science, 9, 75-83.

[5] Nazarenko, A. S., Chinkin, A. S. (2011). Cardiovascular response to vestibular stimulation to cyclic, situational and stereotypical complex coordination kinds of sports. Central European Journal of Sport Sciences and Medicine, 5 (1), 47-52.

[6] Asseman, F. B., Caron, O., Crémieux, J. (2008). Are there specific conditions for which expertise in gymnastics could have an effect on postural control and performance? Gait \& Posture, 27 (1), 76-81. doi: https://doi.org/10.1016/j.gaitpost.2007.01.004

[7] Horak, F. B. (2006). Postural orientation and equilibrium: what do we need to know about neural control of balance to prevent falls? Age and Ageing, 35 (suppl_2), ii7-ii11. doi: https://doi.org/10.1093/ageing/af1077

[8] Ionov, I. A., Komisova, T. Ye., Sliusariev, V. F., Shapovalov, S. O. (2016). Fiziolohiya sensornykh system: metodychni rekomendatsiyi. Kharkiv: ChP Petrov V.V., 45.

[9] Trinus, K. F. (2015). Koreliatsiya zapamorochen z arterialnoiu hipertenzieiu. Mizhnarodnyi nevrolohichnyi zhurnal, 4 (74), $13-19$.

[10] Steele, C. (Ed.) (2012). Applications of EMG in Clinical and Sports Medicine. InTech. doi: https://doi.org/10.5772/2349

[11] Nazarenko, A. S., Chinkin, A. S. (2011). Cardiovascular, motor, and sensory responses to vestibular stimulation in athletes of different specializations. Human Physiology, 37 (6), 726-732. doi: https://doi.org/10.1134/s0362119711050161

[12] Glantz, S. (2012). Primer of biostatistics. New York: McGraw-Hill Medical.

[13] Vovkanych, L., Vynohradskyi, B., Koval, I., Kovtul, O. (2014). Zalezhnist amplitudno-chastotnykh parametriv elektromiohramy vid syly skorochennia miaziv luchnykiv pid chas vykonannia imitatsiynykh vprav. Fizychna aktyvnist, zdorovia i sport, 1 (15), 19-27. 